\section{Patients or clients?}

Sir: As the charm of the word 'client' when used instead of 'patient' has always eluded me, I was delighted to read that the overwhelming majority, namely about $80 \%$, of the patients questioned by Drs Upton, Boer and Neale (Psychiatric Bulletin, March 1994, 18, 142-143) preferred to be called 'patients' rather than 'clients', 'service user', 'customer' or 'consumer'. The social workers, psychologists, nurses and 'carers' of 'clients' and the advocates of 'user' involvement should take note. The word 'patient' is derived from the Latin verb 'pati' (=to suffer) and literally means 'one who suffers' and then, of course, 'someone who suffers from an illness'. The word, at least when used in this sense, does not in itself imply dependence. Those who object to its use because they think that dependence is implied may be interested to know that the word 'patient' has retained this sense only in the curious jargon of modern linguistics, where the subject of a verb is sometimes referred to as the 'actor' and the object of the verb is then called the 'patient'.

Ironically the word 'client', also derived from the Latin ('cliens'=literally 'one who listens', and thus a plebeian dependent on a Roman patrician or patron) is historically much more closely associated with the concept of dependence (compare the expression 'client state') and it was only by about the 17 th century that it began to acquire the meaning of 'someone who makes use of professional services', in short a 'customer'. But in the new agoraphilic (='fond of the marketplace') NHS it is not patients who purchase 'healthcare services' but trust commissioners and fund-holding GPs. Hence the conclusions of Upton et al should not surprise us: patients still prefer to be called what they are rather than what they are not.

P. CRICHTON, Maudsley Hospital, Denmark Hill, London SE5 8AZ

Sir: The issue of the term 'patient' (Psychiatric Bulletin, March 1994, 18, 142-143) is not new. Shortly after he was appointed Superintendent of the McClean Psychiatric Hospital in Boston, Massachusets in 1879, Dr Edward Cowles wrote, "Once within the hospital the conduct of physicians and nurses towards the patient should show that he is regarded as simply ill, as having no reason for being ashamed of his illness. Therefore he should always be called a 'patient' and not a 'boarder', as is the custom in some hospitals and has been in this one from its earliest days. The latter term implies an evasion of the fact of illness, as if it were a disgrace, and by euphemism fosters the very feeling of which we are trying to disabuse the patients."

The term 'patient' evokes connotations of the rights, expectations and obligations of someone who is ill. The understanding of these benefits and obligations are of great use to both the patient and the people looking after him. The use of words such as 'resident' or 'client' which have very different meanings, implying different relationships, may actually be misleading and detrimental to patient staff relationships. The majority of the patients in the survey were comfortable with being called patients and it would seem sensible to remember the adage 'if it ain't broke don't fix it'.

JOHN TAYLOR, Partnerships in Care Ltd, Kneesworth House, Bassingbourn-cum-Kneesworth, Royston, Herts. SG8 5JP

\section{Prescribing drugs in emergencies}

Sir: Cunnane rightly comments on the lack of consensus among psychiatrists when prescribing drugs for rapid tranquillisation (Psychiatric Bulletin, March 1994, 18, 138-139). In particular, it is alarming that $15 \%$ of consultants participating in an emergency on-call rota did not feel competent to give an opinion, and $14 \%$ did not expect to bring the situation under control in under 24 hours. This finding may represent, at least for some sub-specialty consultants, a relative distancing from the acute emergency situation and a lack of familiarity with the available preparations.

We feel it is important to widen discussion on this issue to include the opinion and experiences of junior medical staff. In practice, although a consultant may be available to advise on medication, we believe that responsibility for prescribing in an emergency will frequently fall to the most readily avallable doctor. This may be the ward-based or duty doctor, but in either case he or she is likely to be a senior house officer (SHO) or registrar, making decisions under stressful conditions, often relating to unfamiliar patients and without full information or instance access to advice from senior colleagues. Newly appointed SHOs and GP trainees may have only limited experience in the use of drugs for behavioural control and their potential hazards. Our own study, underway, may shed some light on problems encountered by junior and senior staff.

We were also surprised to find chlorpromazine given as drug of first choice by $50 \%$ of respondents, despite some recommendations to avoid the intramuscular route (Drugs and Therapeutics Bulletin, 29, August 1991). In contrast, no mention was made of zuclopenthixol acetate (Clopixol Acuphase) which is widely used in our practice. This preparation has the advantages of a single, variable dose, rapid onset of action and effects lasting up to three days, although more frequent doses may be given if required. 


\section{CORRESPONDENCE}

In order to maximise efficacy and safety when administering drugs in this manner, it is vital to provide adequate training, perhaps during the induction period for new staff, and regular updates for all grades of staff.

HAYLEY RICHARDS and ELLEN WILKINSON, Blackberry Hill Hospital, Bristol BS16 IDD

\section{Defeat Depression Campaign}

À propos of the letter from Dr Noble (Psychiatric Bulletin, February 1994, 18, 111-112) I do not diminish the value of psychiatric rating scales. My aim in the article he quoted was to show the differing emphases of the depression scales in common use. I am, in fact, an advocate of the need for record of the severity of a disorder by some type of scale; the chart of this, over time, will give invaluable information concerning progress and response to treatment. Our scales have always been accompanied by charts for such records.

What I do warn against is the overinclusive use of terms such as 'depression' and measurement by scales which are a collection of items representing a wide variety of symptoms. I have previously drawn attention to my conviction that psychiatry will not advance as a science until this ingrained attitude is overcome (Snaith, 1993). What is required is closer attention to more discrete aspects of psychopathology, their carefully agreed definition and means of assessment. In this way we may begin to discern the characteristics of disorders which predict particular events, e.g. responses to specific treatments. Recently we have concentrated on the possibility that lowering of hedonic tone is an indication for biological rather than psychological intervention; it is this aspect of mood disorder which is highlighted by the Depression Subscale of our HAD Scale (Zigmond \& Snaith 1983) referred to by Dr Noble.

I should add that I think the Defeat Depression Campaign is not a useful exercise. Simply to provide GPs with lists of symptoms and then to state that there exist effective remedies such as cognitive therapy or pharmacotherapy is of little use. The GP, like the hospital physician, Relate Counsellor or any other person in contact with unhappy, distressed people, requires more exact guidance: the patients who do well with counselling, or cognitive therapy are not the same patients whose distress may be relieved by antidepressant drugs.

SNATH, R.P. (1993) Psychiatry is more than a science: correspondence. British Journal of Psychiatry. 162, 843884.

Zigmond A. \& SNATH, R.P. (1983) The Hospital Anxiety And Depression Scale. Acta Psychiatrica Scandinavica, 67, 361-370.
(Scale with charts etc available from NFER-Nelson, Darville House, 2 Oxford Road East. Windsor, Berks SLA 1BU).

R.P. SNATH, St James's University Hospital, Leeds LS9 TTF

Sir: Thank you for letting me have the opportunity to respond to Dr Snaith's comments on the Defeat Depression Campaign, particularly since he states that the campaign "is not a useful exercise". He seems to predicate his statement on the belief that the campaign will simply "provide GPs with lists of symptoms" and then "state that there exist effective remedies such as cognitive therapy or pharmacotherapy". I am happy to correct this false impression.

The article in the British Medical Journal (Paykel \& Priest, 1992) publishing the results of our consensus meetings, gave a great deal of detail on how recognition and treatment of depression could be improved, particularly in general practice. We did not think that this publication would be read by all doctors and experience in medical education suggests a much more active programme is necessary.

The essential messages of the consensus statement were contained in a readable booklet, circulated to all principals in general practice in Great Britain with the aid of the Department of Health. A further booklet, dealing with the topics more extensively, written by Dr Alastair Wright (editor of the British Journal of General Practice) was sent to all members of the Royal College of General Practitioners. The Management of Depression in Primary Care' is a laminated yellow card, available to all doctors and other health care professionals on request (C5 sized SAE and 25p stamp please). The principal authors of this card are Liz Armstrong and Dr Keith Lloyd. This does list symptoms and provides straightforward advice on management. Maybe this is what Dr Snaith has seen. It has received favourable comment from GPs in pilot studies. In particular, it gives advice on management of patients with different degrees of suicidal potential, including monitoring and referral to specialist care.

Professor Brice Pitt has developed a set of cards for screening elderly patients for depression. The questions are printed in large type, and the questions avoid excessive reliance on features that may be found with physical illnesses so common in the elderly.

However if Dr Snaith is critical about written materials above, he may be more favourably impressed by the training package that is designed to enable general practitioners to improve their skills in the recognition of the depressed patients and in their subsequent treatment and management. The package includes videotapes, written materials and stencils for overhead 